\title{
Choice of birth control methods among European women and the role of partners and providers
}

\author{
Jokin de Irala ${ }^{a, b}$ \\ Alfonso Osorio $b, c$ \\ Silvia Carlos a,b \\ Cristina Lopez-del Burgo ${ }^{\text {a,b, }}{ }^{*}$
}

a Department of Preventive Medicine and Public Health, School of Medicine, University of Navarra, Irunlarrea 1, 31008 Pamplona, Navarra, Spain

${ }^{\mathrm{b}}$ Institute for Culture and Society, University of Navarra, 31008 Pamplona, Navarra, Spain

${ }^{\mathrm{c}}$ Department of Education. University of Navarra, 31008 Pamplona, Navarra, Spain

*Corresponding author:

Tel: +34948425600 (ext. 6360) Fax: +34948425649

E-mail address: cldelburgo@unav.es

Published in:
Contraception
(http://www.contraceptionjournal.org/)

See original article in the Journal's web page:

http://www.sciencedirect.com/science/article/pii/S0010782411001636

Cite as:

de Irala J, Osorio A, Carlos S \& López-del Burgo C (2011). Choice of birth control methods among European women and the role of partners and providers, Contraception, 84, 558-564. 


\begin{abstract}
Background: The choice of a birth control method is influenced by socio-cultural and personal factors. We explored the perceived influences in women's choice of a birth control method in five European countries (Germany, France, the U.K., Romania and Sweden), where contraception is widely used.
\end{abstract}

Study design: Cross-sectional study of 1137 randomly selected women, aged 18-49 years. An anonymous, 31-item questionnaire related to birth control methods was used. Logistic regression was used to identify variables associated with partner participation in choice of a contraceptive.

Results: Oral contraceptives were mainly used in Germany (54.3\%), France (50.5\%) and Sweden (34.6\%) and condoms in the UK (29.6\%) and Romania (22.9\%). Sweden showed the highest use of intrauterine devices (19\%). Romania had the lowest use of contraception. Oral contraceptives and intrauterine devices use were frequently suggested by providers instead of by women. Choosing the method with the partner was associated with age $(\mathrm{OR}=0.97,95 \% \mathrm{CI} \quad 0.94-0.99)$, university graduate $(\mathrm{OR}=1.59,95 \% \mathrm{CI} 1.01-2.29)$, married $(\mathrm{OR}=1.52,95 \% \mathrm{CI} 1.01-2.29)$ and with using a method that requires partner's cooperation $(\mathrm{OR}=8.18,95 \% \mathrm{CI} 5.46-12.27)$.

Conclusions: Hormonal contraceptives and intrauterine devices are commonly recommended by providers rather than requested by women. Partner preferences are taken into account when his cooperation in the use of the method is needed. As fertility care is a male and female issue, there is still more room for actively involving both women and men in choice of a birth control method.

Key words: birth control methods, condoms, oral contraceptives, intrauterine devices, informed choice. 


\section{Introduction}

Although contraception is widely used in Europe, there are different patterns of use among countries. Studies conducted in the $90 \mathrm{~s}$ and thereafter, showed that oral contraceptives (OCs) were the most popular method, especially in Czech Republic, France and Germany. Condoms were widely used in Spain and Italy. While less reliable methods, such as withdrawal or female barrier methods, were more popular in the Baltic States and Russia, intrauterine devices (IUDs) were more commonly used in Denmark and Sweden than in other European countries [1-4].

When choosing a method, its characteristics as well as socio-cultural and personal factors are taken into account. Efficacy, adverse effects, accessibility or convenience are frequently cited by women as important features when choosing a method [5]. But personal beliefs, reproductive intentions, marital status or sexual lifestyles also influence women's choice $[6,7]$. A study carried out in several European countries found that contraceptive use, in general, was more common among single, highly educated women and those with several children [1]. In a study performed in Spain, beliefs about when human life begins was associated with women's potential decisions about using family planning (FP) methods with postfertilization and postimplantation effects [8].

Informed choices in FP are associated with better satisfaction and compliance with the method, and consequently with less failures [9]. Health care providers are an important source of information about FP and their opinions about specific methods can also influence women's choices [10]. Physicians with misconceptions or incomplete information about a specific method may hinder women from making properly informed choices [11]. Furthermore, as fertility care involves women and men, male partner opinions could also influence the choice of a FP method [12]. 
In this study, we explored the perceived influences in women's choice of a FP method in five European countries (Germany, France, the U.K., Romania and Sweden). We hypothesized that women's choice of a FP method was influenced more by health care providers than by their male partners.

\section{Methods}

\subsection{Study design}

The study was carried out as a cross-sectional survey of randomly selected women, aged 18-49 years, in five European countries (Germany, France, the UK, Sweden and Romania). These countries were chosen because they have different patterns of FP and diverse socio-cultural settings. Budgetary limitations precluded implementing the survey in more countries. Spain was not included because a similar survey had previously been conducted there [8].

This study was designed mainly to estimate the proportion of European women that would hypothetically consider using or not a method with possible postfertilization effects (we did not ask about specific contraceptive methods). In a previous study in Spain, $45 \%$ of women would not use methods with postfertilization effects. Taking into account this proportion, with a confidence level of $95 \%$ and a precision of $\pm 6 \%$, the required sample size in each country was approximately 264. Due to budgetary constrains we ended up with smaller samples $(\approx 200)$ with a resulting precision of $\pm 6.9 \%$. Furthermore, a multivariate analysis was needed to evaluate associations and adjust for confounders. We worked with the criteria that 10 subjects would be needed for each continuous variable and/or each dummy variable from categorical variables included in a statistical model to adjust for confounding [13]. An overall sample size of about 1000 subjects (approximately 200 per country) was sufficient to meet these needs. 
Women under 18 or above 49 , those who had any surgery or pre-existing conditions causing them to be infertile or sterile, pregnant women and those who were trying to get pregnant were excluded. We did not exclude women with an infertile or sterilized male partner because we assumed that those women could be using contraception to avoid pregnancy in case they had a sexual relationship with another man.

The study was approved by the Ethic Committee of the University of Navarra.

\subsection{Sampling and data collection}

An international market research company (GFK Group) performed the sampling and collected the data. This company is not related to any pharmaceutical industry or any other kind of industry.

To obtain a nationally representative sample of women in each country, recruitment quotas per age were set according to country-specific official statistics. After stratification by geographic location and population size of residence, a computer program randomly chose census sections and routes. Once in the route, women from households that met the above mentioned criteria to enter the study (18 to 49 years old with no infertility declared, non pregnant and not trying to get pregnant), were invited to participate. In Sweden and the UK, women were randomly selected from a panel, set by the research market company. These women were invited to participate via email.

Data were collected between October and December of 2008 by researchers from the market research company. Firstly, they gave participants a letter explaining that filling out the questionnaire constituted voluntary participation. Participants did not receive any incentive. The questionnaire was self-administered using the Computer-Assisted Personal Interviewing (CAPI) method in France, Germany and Romania and Web-based interviews in Sweden and the UK. 


\subsection{Questionnaire}

An anonymous, self-administered, 31-item questionnaire about knowledge, beliefs and attitudes related to mechanisms of action of FP methods was administered to participants. Sometimes induced abortion is used as a FP method [14], so it was also listed among the methods. This questionnaire was previously implemented in Spain and in the USA; details of these studies were published elsewhere $[5,15]$. Briefly, the questionnaire included questions about participants' reproductive history, past and current use of any birth control method, the importance they attached to various features of the different methods and their opinions about mechanisms of action of birth control methods. Women using a method were asked if it was suggested by the physician or requested by themselves and if they discussed the choice with their partner. Information about sexual behavior was not requested from the participants. Socio-demographic information was asked at the conclusion of the questionnaire. There were no open ended questions. Data collected in the questionnaire, and not included in this paper, have not been published yet.

The questionnaire was originally developed in English, translated into local languages by native speakers from the market research company and then back again into English to assess the accuracy of the translations. The English version was previously validated by assessing consistency of responses [15]. No additional verbal information was given to the participants. The English version is available from the authors upon request.

\subsection{Analysis}

Data were analyzed using the statistical software SPSS version 15.0. We calculated proportions and their confidence intervals based on the normal approximation. We performed Chi-square tests to compare the proportions of use of birth control methods among countries. We used non-conditional logistic regression to assess the characteristics 
independently associated with making a joint male and female decision about using a FP method.

Independent variables were age, marital status, educational level, socioeconomic status, parity, religious beliefs, desire of future pregnancy, previous induced abortion and country of origin. Because of differences in the educational systems across Europe, the education variable was recoded in two categories: (1) low, medium and (2) high (university). Marital status was recoded as a dichotomous variable (married/unmarried).

\section{Results}

\subsection{Characteristics of the sample}

A total of 1137 women were finally included in the study. Number of excluded women was not recorded and no formal response rate was calculated. When a woman declined to participate in the study, and in order to reach the target sample size, another woman was randomly selected from a pool of women complying with similar eligibility criteria.

Socio-demographic characteristics of each country are shown in Table 1. Romania had the largest proportion of married women and Sweden the lowest. The highest proportion of nulliparae was found in France (66.8\%) and the lowest in Romania (30.8\%).

\subsection{Ever and current contraceptive use}

The majority of the European women (88.1\%) have ever used a contraceptive method. Romania had the lowest percentage of ever use $(67.4 \%)$ and Sweden the highest (96.7\%). The most common methods ever used by all the surveyed European women were OCs $(70.4 \%)$, condoms (63.2\%), withdrawal (25.5\%) and IUDs (16.3\%). The least frequently ever used methods were the hormonal patch $(0.4 \%)$, the vaginal ring $(2.6 \%)$ and modern fertility awareness-based methods (FAB) (2.8\%). France and Sweden had the 
highest proportion of self-reported postcoital pill use (26.7\% and $25.2 \%$ respectively), while Romania the lowest (4.4\%).

In relation to current use, taking into account all the surveyed women, the most popular methods in order of frequency were OCs, condoms and the IUD. Specifically, OCs were the most often used method in Germany (54.3\%), France (50.5\%) and Sweden (34.6\%), while in the UK and Romania, the most often method used was the condom $(29.6 \%$ and $21.6 \%$, respectively). IUDs were the third most common method in the five countries, with the highest proportion in Sweden (19\%) and the lowest in Romania (3.5\%) (Table 2). Condoms were mainly used combined with OCs in all the countries. When considering the condom as the only current method, the overall percentage was lower $(12.8 \%)$, especially in Germany (6.5\%) and France (11.9\%). Twenty-three per cent of all participants reported not using any method at the time of the survey (Table 2).

\subsection{Decision making about method use}

Women were asked how they chose the method currently used. For current users of methods that require medical control or prescription, such as hormonal methods and IUDs, the choice of method was suggested or recommended by the physician rather than the woman in the majority of cases $(69.5 \%$ in OC users and $79.4 \%$ in IUD users). On the contrary, the methods that need partner's cooperation such as condoms, withdrawal or FAB methods were mainly proposed by the women $(82.5 \%, 81.8 \%$ and $60 \%$, respectively) (Table 3).

We found that $63.3 \%$ of the women reported having discussed the use of the method with their partner. Among these, $45.2 \%$ jointly decided which method to use with their partner. The methods chosen with greater partner participation were, by order of frequency: calendar methods, female barriers, condoms, withdrawal and male sterilization (Table 3). After adjusting for socio-demographic characteristics, making a joint decision was 
associated with being married $(\mathrm{OR}=1.52 ; 95 \% \mathrm{CI}=1.01-2.29)$, having a university education $(\mathrm{OR}=1.59 ; 95 \% \mathrm{CI}=1.04-2.46)$ and with age $(\mathrm{OR}=0.97,95 \% \mathrm{CI}=0.94-0.99)$. That is, for every year increase in age, the odds for making a joint decision was $3 \%$ lower. Current use of a method that requires partner's cooperation, such as condoms, withdrawal or FAB methods, was also strongly associated with making a joint choice $(\mathrm{OR}=8.18 ; 95 \% \mathrm{CI}=5.46-$ 12.27).

\section{Discussion}

This study provides information about the perceived role of partners and physicians in determining women's choices of a birth control method.

According to United Nations (UN), prevalence of contraceptive use in Europe among women of reproductive age (15-49 years old) who are married or in union, is around 70\% [16]. Specifically, OCs and IUDs are the most popular methods in France, Germany and Sweden, condoms are highly used in the UK and withdrawal is the most popular method in Romania. The patterns of contraceptive use found in our study are consistent with these data and with other European surveys [2, 4].

Sociocultural factors, such as religious teachings or cultural norms about sexuality and family, and availability of contraceptive methods in individual countries may influence the different patterns of contraception [7, 17]. Although a large array of methods is available in the countries of our study, methods such as hormonal contraceptives or the IUD, were prohibited in Romania during the past decades, being available since the 90s [18]. This fact could explain that Romania has the lowest use of contraception, compared with the other countries where several contraceptive methods were available decades before. We also found a high rate of reported induced abortion in Romania, consistent with European data [19]. Some authors suggest that high use of less effective methods, such as withdrawal, and high rates of discontinuation seem to have led Romanian women to seek induced abortions 
during the last decades [20]. In our study, the highest proportion of self-reported postcoital pill use was found in France and Sweden, where emergency contraception (EC) is available over the counter, and the lowest in Romania, where a medical prescription is required.

Among women using a method that requires medical services (e.g. hormonal contraceptives or IUDs), a high percentage stated that it was recommended or suggested by the doctor. This was also found in another European survey in which, the choice of current users of an OC was recommended by the physician or gynecologist rather than the woman in $75 \%$ of cases [4]. This is not surprising as physicians are considered a reliable source of information about FP [21], and their opinions can influence the choice of couples [11]. But sometimes, physicians do not have adequate information about specific methods, hindering informed choices by couples. A study conducted in the U.K. found that physicians with misconceptions about the side effects of long-acting contraceptives were less likely to suggest them to women [22]. Another study among family medicine providers in the USA found that $37 \%$ were wrong about the timing for administrating the EC pill and $25 \%$ were unsure about its mechanism of action [23]. Therefore, it is essential that FP providers have adequate and updated knowledge about the methods available for couples.

As shown above, FP providers play an important role assessing about medical eligibility criteria for contraceptive use and providing the necessary information for couples to make fully informed decisions [24]. On the other side, better adherence and subsequently higher effectiveness is found when women choose the method they really want [25]. So, a balance between recommendations of the physicians and the desires of the couple is required.

The 1994 Conference on Population and Development in Cairo highlighted the need for men's involvement in sexual and reproductive health issues [26]. The low participation of male partners in contraceptive choices found in our study is in accordance with other 
studies $[27,28]$. Although fertility involves men and women, it is still considered by many to be a woman's responsibility [29]. Nowadays, nearly all effective FP methods are targeted exclusively to women. Only condoms and vasectomy are male-used methods. Modern FAB methods are rarely used in spite of their effectiveness and promotion of mutual responsibility on fertility care [30]. In addition, reproductive health services are mainly focused on women, so men are frequently out of the contraceptive decision-making process. In fact, in our study, we found that the final decision of using a specific method was usually taken by the women. There is still more room for actively involving both women and men in FP. For example, the "Fertility Management Program", a research project supported by the Socrates Program from the European Union, was developed to, among other goals, "encourage and support a common decision-making regarding family planning”. The program offered adult educators the necessary qualifications for dealing with couples on topics related to fertility and sexuality, as well as FP and life perspective with regard to gender-specific aspects [31]. Similar initiatives should be encouraged to empower men and women to manage their own fertility together.

Our study has some limitations. The first one has to do with sample sizes in each country. The sample size estimation does not depend only on statistical factors. Cost, population size or ethical issues may also determine the sample size estimation of a study [32]. A sample size of 200 per country, with a statistical accuracy of $\pm 6 \%$, was more in line with our budget. Furthermore, we wanted to explore the associations with joint partner choice, for which adjusting for confounding is important. According to the criterion that 10 subjects would be needed for each parameter included in a statistical model to adjust for confounding [13], our global sample size of 1137 was sufficient for these purposes.

For statistical analyses, we recoded "marital status" in married/unmarried. We are aware that long-term partnered women in Sweden may have more similarities to married 
than unmarried women. But in other countries, where cohabitation is not so frequent, women who responded "single" could be in fact living with their partner. Furthermore, we did not know how long women had been living with their partner. This possible misclassification would dilute the effect of "marital status" on the outcome assessed in the study. In spite of the possible bias towards the null, we did find that being married was associated with making a joint decision about FP.

The following considerations speak in favor of the face validity and representativeness of our results. The percentage of married women in our study was high in Romania, where marriage is still part of the culture pattern [33], and low in Sweden, where cohabitation is more common [34]. According to the European Mindset Study, the highest percentages of non-religious population correspond to U. Kingdom (50\%), France $(46 \%)$ and Sweden (41\%) [35]. On the contrary, nearly everyone in Romania has a religion [33]. Data from the Organization for Economic Cooperation and Development (OECD) show that percentages of university educated women in Germany, France, U. Kingdom, Romania and Sweden are $21 \%, 33.2 \%, 33 \%, 10.6 \%$ and $44 \%$, respectively [36]. These figures are similar to those found in our study. It has to be noted that our sample encompasses women aged 1849 years, while the Mindset Study refers to the entire population and the OECD to women aged 25-64 years.

A strength of our study is that the questionnaire was self-administered in all the countries to avoid the interviewer bias. Furthermore, the same questionnaire was used in all countries. Sampling and data collection was conducted by the GFK-Emer company, belonging to the fourth market research group in the world and holding European Quality certifications [37].

The majority of European surveys about FP focus on patterns of use of methods among countries. To our knowledge, this is the first study that also explores the perceived 
influences in women's choice of a FP method in a representative sample of five European countries.

\section{Conclusion}

Hormonal contraceptives and IUDs are commonly recommended by providers instead of requested by women. Partner preferences are taken into account mostly when their cooperation in the use of the method is needed. As fertility care is a male and female issue, there is still more room for actively involving both women and men in the process of choosing a birth control method.

\section{Acknowledgements}

We thank Mathew Hanley for editing and proof reading the English and Dr. Joseph Stanford (University of Utah) and Dr. Rafael Mikolajczyk (University of Bielefeld) who first studied this issue in the USA. Dr. Stanford commented on our analysis. We also thank the European women who participated in our study. This study was funded by the Institute of Family Sciences, University of Navarra. 


\section{References}

[1] Spinelli A, Talamanca IF, Lauria L. Patterns of contraceptive use in 5 European countries. European Study Group on Infertility and Subfecundity. Am J Public Health 2000;90:1403-8.

[2] Cibula D. Women's contraceptive practices and sexual behaviour in Europe. Eur J Contracept Reprod Health Care 2008;13:362-75.

[3] Pérez Campos E. Uso de los distintos métodos anticonceptivos por las mujeres españolas. Prog Obstet Ginecol 2005;48 (supl 1):S216-19.

[4] Skouby SO. Contraceptive use and behavior in the 21st century: a comprehensive study across five European countries. Eur J Contracept Reprod Health Care 2004;9:5768 .

[5] De Irala J, Lopez del Burgo C, de Fez CM, Arredondo J, Mikolajczyk RT, Stanford JB. Women's attitudes towards mechanisms of action of family planning methods: survey in primary health centres in Pamplona, Spain. BMC Womens Health 2007;7:10.

[6] Oddens BJ, Lehert P. Determinants of contraceptive use among women of reproductive age in Great Britain and Germany. I: Demographic factors. J Biosoc Sci 1997;29:41535 .

[7] Srikanthan A, Reid RL. Religious and cultural influences on contraception. J Obstet Gynaecol Can 2008;30:129-37.

[8] Lopez-del Burgo C, Lopez-de Fez CM, Osorio A, Guzman JL, de Irala J. Spanish women's attitudes towards post-fertilization effects of birth control methods. Eur J Obstet Gynecol Reprod Biol 2010;151:56-61.

[9] Frost JJ, Singh S, Finer LB. Factors associated with contraceptive use and nonuse, United States, 2004. Perspect Sex Reprod Health 2007;39:90-9.

[10] Dehlendorf C, Levy K, Ruskin R, Steinauer J. Health care providers' knowledge about contraceptive evidence: a barrier to quality family planning care? Contraception 2010;81:292-8.

[11] Stubbs E, Schamp A. The evidence is in. Why are IUDs still out?: Family physicians' perceptions of risk and indications. Can Fam Physician 2008;54:560-6.

[12] Grady WR, Klepinger DH, Billy JO, Cubbins LA. The role of relationship power in couple decisions about contraception in the US. J Biosoc Sci 2010:1-17.

[13] Vittinghoff E, McCulloch CE. Relaxing the rule of ten events per variable in logistic and Cox regression. Am J Epidemiol 2007;165:710-8.

[14] Kulczycki A, Potts M, Rosenfield A. Abortion and fertility regulation. Lancet 1996;347:1663-8.

[15] Dye HM, Stanford JB, Alder SC, Kim HS, Murphy PA. Women and postfertilization effects of birth control: consistency of beliefs, intentions and reported use. BMC Womens Health 2005;5:11.

[16] United Nations Population Division. World contraceptive use 2009. Available in: http://www.un.org/esa/population/publications/contraceptive2009/contraceptive2009.ht $\underline{\mathrm{m}}$.

[17] Oddens BJ. Determinants of contraceptive use among women of reproductive age in Great Britain and Germany. II: Psychological factors. J Biosoc Sci 1997;29:437-70. 
[18] Serbanescu F, Morris L, Stupp P, Stanescu A. The impact of recent policy changes on fertility, abortion, and contraceptive use in Romania. Stud Fam Plann 1995;26:76-87.

[19] Sedgh G, Henshaw SK, Singh S, Bankole A, Drescher J. Legal abortion worldwide: incidence and recent trends. Int Fam Plan Perspect 2007;33:106-16.

[20] Creanga AA, Acharya R, Ahmed S, Tsui AO. Contraceptive discontinuation and failure and subsequent abortion in Romania: 1994-99. Stud Fam Plann 2007;38:23-34.

[21] van Lunsen RH, Arnolds HT, van Maris MG. Choices and changes in contraceptive behaviour; the role of information sources. Patient Educ Couns 1994;23:197-202.

[22] Wellings K, Zhihong Z, Krentel A, Barrett G, Glasier A. Attitudes towards long-acting reversible methods of contraception in general practice in the UK. Contraception 2007;76:208-14.

[23] Wallace JL, Wu J, Weinstein J, Gorenflo DW, Fetters MD. Emergency contraception: knowledge and attitudes of family medicine providers. Fam Med 2004;36:417-22.

[24] Upadhyay UD. Informed choice in family planning. Helping people decide. Popul Rep J 2001:1-39.

[25] Branden PS. Contraceptive choice and patient compliance. The health care provider's challenge. J Nurse Midwifery 1998;43:471-82.

[26] United Nations. Report on the International Conference in Population and Development, Cairo, 5-13 September 1994. New York: United Nations; 1994.

[27] Cox S, Posner SF, Sangi-Haghpeykar H. Who's responsible? Correlates of partner involvement in contraceptive decision making. Women's Health Issues 2010;20:254-9.

[28] O'Campo P, Faden RR, Gielen AC, Kass N, Anderson J. Contraceptive and sexual practices among single women with an unplanned pregnancy: partner influences. Fam Plann Perspect 1993;25:215-9.

[29] Ekstrand M, Tyden T, Darj E, Larsson M. Preventing pregnancy: a girls' issue. Seventeen-year-old Swedish boys' perceptions on abortion, reproduction and use of contraception. Eur J Contracept Reprod Health Care 2007;12:111-8.

[30] Frank-Herrmann P, Heil J, Gnoth C, et al. The effectiveness of a fertility awareness based method to avoid pregnancy in relation to a couple's sexual behaviour during the fertile time: a prospective longitudinal study. Hum Reprod 2007;22:1310-9.

[31] Fertility Management Program. Project \# 229793-CP-1-2006-1-DE-GRUNDTVIGG11 (wwwfertilitymgteu).

[32] Lenth R. Some practical guidelines for effective sample-size determination. Am Statician 2001;55:187-93.

[33] National Institute of Statistics of Romania. Romania in figures 2010.

[34] Statistics Sweden. Women and men in Sweden. Facts and figures 2010.

[35] BBVA Foundation. European Mindset Study 2010. Available in: http://wwwfbbvaes/TLFU/dat/european_mindset_27042010pdf.

[36] Organization for Economic Cooperation and Development. Education at a Glance 2009: OECD Indicators (wwwoecdorg/edu/eag2009).

[37] GFK-Emer Market Research. (www.gfk-emer.com). 
Table 1. Characteristics of the participants

\begin{tabular}{|c|c|c|c|c|c|c|}
\hline Characteristics & $\begin{array}{c}\text { Germany } \\
(\mathrm{N}=199) \\
\%\end{array}$ & $\begin{array}{c}\text { France } \\
(\mathbf{N}=\mathbf{2 0 2}) \\
\%\end{array}$ & $\begin{array}{c}\text { U. Kingdom } \\
\begin{array}{c}(\mathbf{N}=\mathbf{2 0 3}) \\
\%\end{array}\end{array}$ & $\begin{array}{c}\text { Romania } \\
(\mathbf{N}=227) \\
\%\end{array}$ & $\begin{array}{c}\text { Sweden } \\
(\mathbf{N}=306) \\
\%\end{array}$ & $\begin{array}{c}\text { Total } \\
(\mathbf{N}=1137) \\
\%\end{array}$ \\
\hline \multicolumn{7}{|l|}{ Age, years } \\
\hline $18-24$ & 17.6 & 27.2 & 18.7 & 22.0 & 31.4 & 24.1 \\
\hline $25-34$ & 27.6 & 41.1 & 30.5 & 34.8 & 27.8 & 32.0 \\
\hline $35-49$ & 54.8 & 31.7 & 50.7 & 43.2 & 40.8 & 43.9 \\
\hline \multicolumn{7}{|l|}{ Education } \\
\hline Low, medium & 75.4 & 66.8 & 69.0 & 80.2 & 54.2 & 68.0 \\
\hline High (university) & 24.6 & 33.2 & 31.0 & 19.8 & 45.8 & 32.0 \\
\hline \multicolumn{7}{|l|}{ Marital status } \\
\hline Unmarried & 50.3 & 57.4 & 52.2 & 26.0 & 72.9 & 52.0 \\
\hline Married & 49.7 & 42.6 & 47.8 & 74.0 & 27.1 & 48.0 \\
\hline \multicolumn{7}{|c|}{ Socioeconomic status* } \\
\hline Low & 3.5 & 15.8 & 22.8 & 23.3 & 46.4 & 23.3 \\
\hline Medium & 77.4 & 67.3 & 70.8 & 60.4 & 42.3 & 62.8 \\
\hline High & 19.1 & 16.8 & 6.4 & 16.3 & 11.3 & 13.9 \\
\hline \multicolumn{7}{|l|}{ Parity (No. births) } \\
\hline 0 & 38.2 & 66.8 & 29.6 & 30.8 & 56.9 & 40.9 \\
\hline 1 & 25.6 & 11.4 & 20.2 & 28.6 & 7.8 & 17.9 \\
\hline $2+$ & 36.2 & 21.7 & 50.2 & 40.6 & 35.3 & 41.2 \\
\hline \multicolumn{7}{|l|}{$\begin{array}{l}\text { Previous induced } \\
\text { abortion }^{\dagger}\end{array}$} \\
\hline No & 97.0 & 84.2 & 89.2 & 80.6 & 84.3 & 86.6 \\
\hline Yes & 3.0 & 15.8 & 10.8 & 19.4 & 15.7 & 13.4 \\
\hline \multicolumn{7}{|l|}{$\begin{array}{l}\text { Desire of future } \\
\text { pregnancy }\end{array}$} \\
\hline Yes, probably yes & 28.8 & 60.5 & 30.0 & 28.6 & 50.9 & 40.7 \\
\hline Unsure & 7.6 & 6.0 & 15.3 & 6.9 & 8.2 & 8.7 \\
\hline No, probably no & 63.6 & 33.5 & 54.7 & 64.5 & 40.8 & 50.6 \\
\hline \multicolumn{7}{|l|}{ Religion } \\
\hline None & 33.2 & 55.4 & 60.6 & 0.4 & 59.8 & 42.7 \\
\hline Catholic & 29.6 & 34.7 & 8.9 & 5.3 & 1.6 & 14.4 \\
\hline Other Christians & 34.7 & 1.0 & 21.2 & 88.1 & 32.7 & 36.4 \\
\hline Others $^{\#}$ & 2.5 & 8.9 & 9.4 & 6.2 & 5.9 & 6.5 \\
\hline
\end{tabular}

*According to total household income and occupation of the head of household.

†Self-reported data.

Other Christians: includes Anglican, Orthodox, Protestant and Evangelical.

${ }^{\#}$ Others: includes Buddhism, Hinduism, Jewish, Muslim, Jehovah Witness and others not specified. 
Table 2. Current birth control methods used by women, by country

\begin{tabular}{|c|c|c|c|c|c|c|}
\hline Birth control method & $\begin{array}{c}\text { Germany } \\
\mathbf{N}=\mathbf{1 9 9} \\
\%(95 \% \mathrm{CI}) \\
\end{array}$ & $\begin{array}{c}\text { France } \\
\mathbf{N}=\mathbf{2 0 2} \\
\%(95 \% \mathrm{CI}) \\
\end{array}$ & $\begin{array}{c}\text { U. Kingdom } \\
\mathbf{N}=\mathbf{2 0 3} \\
\%(95 \% \mathrm{CI}) \\
\end{array}$ & $\begin{array}{c}\text { Romania } \\
\mathbf{N}=\mathbf{2 2 7} \\
\%(95 \% \mathrm{CI}) \\
\end{array}$ & $\begin{array}{c}\text { Sweden } \\
\mathbf{N}=\mathbf{3 0 6} \\
\%(95 \% \mathrm{CI}) \\
\end{array}$ & $\begin{array}{c}\text { Total } \\
\mathbf{N}=\mathbf{1 1 3 7} \\
\%(95 \% \mathrm{CI}) \\
\end{array}$ \\
\hline Oral contraceptives & $54.3(47.1-61.3)$ & $50.5(43.4-57.6)$ & $23.6(18.0-30.1)$ & $21.6(16.4-27.5)$ & $34.6(29.3-40.3)$ & $36.3(33.5-39.2)$ \\
\hline Male condom & $13.1(8.7-18.5)$ & $33.2(26.7-40.1)$ & $29.6(23.4-36.3)$ & $22.9(17.6-28.9)$ & $22.5(17.9-27.6)$ & $24.1(21.6-26.7)$ \\
\hline Intrauterine device & $5.0(2.4-9.1)$ & $13.4(9.0-18.8)$ & $10.3(6.5-15.4)$ & $3.5(1.5-6.8)$ & $19.0(14.7-23.8)$ & $10.9(9.1-12.9)$ \\
\hline Withdrawal & $1.5(0.3-4.3)$ & $7.4(4.2-11.9)$ & $3.0(1.1-6.3)$ & $10.6(6.9-15.3)$ & $9.8(6.7-13.7)$ & $6.9(5.5-8.5)$ \\
\hline Calendar methods* & $2.5(0.8-5.8)$ & $1.5(0.3-4.3)$ & $2.5(0.8-5.6)$ & $12.3(8.4-17.3)$ & $4.9(2.8-8.0)$ & $4.8(3.7-6.2)$ \\
\hline Hormonal injectable & $2.0(0.6-5.1)$ & 0 & $5.4(2.7-9.5)$ & $0.9(0.1-3.1)$ & $2.0(0.7-4.2)$ & $2.0(1.3-3.0)$ \\
\hline Hormonal implant & $1.0(0.1-3.6)$ & $1.5(0.3-4.3)$ & $3.9(1.7-7.6)$ & 0 & $2.6(1.1-5.1)$ & $1.8(1.1-2.8)$ \\
\hline Female barrier ${ }^{\dagger}$ & $1.0(0.1-3.6)$ & $2.5(0.8-5.7)$ & $1.0(0.1-3.5)$ & $1.8(0.5-4.4)$ & 0 & $1.1(0.5-1.8)$ \\
\hline Modern FAB methods* & $1.0(0.1-3.6)$ & $1.0(0.1-3.5)$ & $1.5(0.3-4.3)$ & $0.4(0.0-2.4)$ & $1.3(0.4-3.3)$ & $1.1(0.5-1.8)$ \\
\hline Vaginal ring & $2.0(0.6-5.1)$ & 0 & 0 & $0.9(0.1-3.1)$ & $1.6(0.5-3.8)$ & $1.0(0.5-1.7)$ \\
\hline Contraceptive patch & 0 & 0 & 0 & 0 & $0.3(0.0-1.8)$ & $0.1(0.0-0.5)$ \\
\hline Male sterilization & $1.5(0.3-4.3)$ & 0 & $4.4(2.0-8.2)$ & 0 & $0.3(0.0-1.8)$ & $1.1(0.5-1.8)$ \\
\hline No method & $23.1(17.4-29.6)$ & $13.9(9.4-19.4)$ & $26.6(20.7-33.2)$ & $40.5(34.1-47.2)$ & $13.7(10.1-18.1)$ & $23.0(20.6-25.6)$ \\
\hline
\end{tabular}

Chi-square tests showed significant differences among the 5 countries for every method ( $p<0.05)$ except for the vaginal ring, the contraceptive patch and FAB (fertility awareness based) methods. 95\% CI: 95\% confidence interval.

Column totals may exceed $100 \%$ as women could be using more than one method.

* Calendar method: includes Rhythm method (Ogino method) and "avoiding days when it is more likely to get pregnant, without using a specific rule".

${ }^{\dagger}$ Female barrier: cervical cap, diaphragm, female condom.

* Modern FAB (fertility awareness-based) methods: Billings method, Sympothermal method, Lactational-Amenorrhea method and devices that identify fertility. 
Table 3. Women's decision making about the birth control method they currently use

\begin{tabular}{|c|c|c|c|c|c|}
\hline \multirow[b]{2}{*}{ Birth control method (n) } & \multicolumn{2}{|c|}{$\begin{array}{l}\text { How did you choose or decide on what birth } \\
\text { control method to currently use?* }\end{array}$} & \multicolumn{3}{|c|}{$\begin{array}{l}\text { How, if at all, did your partner participate } \\
\text { in the choice of the birth control method?* }\end{array}$} \\
\hline & $\begin{array}{c}\text { Doctor suggestion or } \\
\text { recommendation } \\
\%\end{array}$ & $\begin{array}{c}\text { Own request } \\
\%\end{array}$ & $\begin{array}{l}\text { My own } \\
\text { decision } \\
\%\end{array}$ & $\begin{array}{c}\text { My partner's } \\
\text { decision } \\
\%\end{array}$ & $\begin{array}{c}\text { Joint } \\
\text { decision } \\
\%\end{array}$ \\
\hline Oral contraceptives (331) & 69.5 & 30.5 & 84.2 & 0.9 & 14.8 \\
\hline Male condom (126) & 17.5 & 82.5 & 31.7 & 5.6 & 62.7 \\
\hline Intrauterine device (107) & 79.4 & 20.6 & 82.1 & 0 & 17.9 \\
\hline Withdrawal (16) & 0 & 100 & 28.6 & 9.5 & 61.9 \\
\hline Calendar methods ${ }^{\dagger}(22)$ & 18.2 & 81.8 & 33.3 & 0 & 66.7 \\
\hline Hormonal injectable (22) & 71.4 & 28.6 & 95 & 0 & 5 \\
\hline Hormonal implant (17) & 64.7 & 35.3 & 85.7 & 0 & 14.3 \\
\hline Female barrier ${ }^{*}(4)$ & 50 & 50 & 33.3 & 0 & 66.7 \\
\hline Vaginal ring (9) & 77.8 & 22.2 & 88.9 & 0 & 11.1 \\
\hline Modern FAB methods ${ }^{\S}(5)$ & 40 & 60 & 62.5 & 12.5 & 25 \\
\hline Contraceptive patch (1) & 100 & 0 & - & - & - \\
\hline Male sterilization (12) & 25 & 75 & 16.7 & 25 & 58.3 \\
\hline $\begin{array}{l}* \text { The table displays respon } \\
+ \text { Calendar method: includ } \\
\text { specific rule". } \\
\S \text { Female barrier: cervical c } \\
\text { \%odern FAB (fertility a } \\
\text { devices that identify fertil }\end{array}$ & $\begin{array}{l}\text { Nomen using exclusivel } \\
\text { thm method (Ogino) a } \\
\text { phragm, female condom } \\
\text { ss-based) methods: Bi }\end{array}$ & $\begin{array}{l}\text { one birth control metho } \\
\text { "avoiding days when } \\
\text { igs method, Sympothe }\end{array}$ & method, Lac & onal-Amenorr & $\begin{array}{l}\text { thout using a } \\
\text { method and }\end{array}$ \\
\hline
\end{tabular}

